\title{
A comunidade católiea Obra de Maria: formas de sociabilidade, estilo de vida e catolicismo contemporâneo
}

\section{The catholic community Work of Mary: forms of sociability, lifestyle and contemporary Catholicism}

\section{Carlos André Cavalcanti* Anderson Cordeiro de Moura**}

Recebido: 21/01/2018. Aprovado: 23/04/2018.

Resumo: $O$ advento do movimento carismático em fins do século XX propulsionou uma reconfiguração do catolicismo tradicional, cuja maior expressão verifica-se com o surgimento de uma nova forma de vivência da fé cristã, por meio das Novas Comunidades Carismáticas. Neste sentido, analisamos, neste trabalho, a Comunidade Católica Obra de Maria, destacando aspectos relevantes, bem como seu desenvolvimento, sua estrutura, seus projetos sociais, sua vida comunitária, seu papel na Igreja, e suas práticas religiosas. Para tanto, adotamos a pesquisa descritiva e de natureza bibliográfica. Tomamos como referência a Obra de Carranza, Mariz e Camurça (2009), assim como o conceito de ação comunitária da religião, conforme Weber (1991), que nos permite compreender o sentido através das vivências, das representações e dos fins subjetivos dos indivíduos. Assim, a partir das práticas que emergem no seio deste movimento, examinamos o sentido que ela tem entre os seus adeptos e para a Igreja na atualidade.

Palavras-chave: Novos Movimentos. Catolicismo. Religiosidade

* Pós-Doutor em Ciências da Religião (PUC Goiás, Goiânia-GO, 2018). Doutor em História (UFPE, Recife-PE, 2001). Professor Doutor da UFPB. Líder dos Grupos Videlicet Religiões, de Estudos em Intolerância, Diversidade e Imaginário do PPGCR/UFPB.

E-mail: carlosandrecavalcanti@gmail.com.

** Mestrando pelo Programa de Pós-Graduação em Ciências das Religiões da Universidade Federal da Paraíba-UFPB. Graduado em História (Faculdade de Formação de Professores de Goiana (FADIMAB), Goiana-PE, 2015). Especialização em História do Brasil (Faculdade de Formação de Professores de Goiana (FADIMAB), Goiana-PE, 2016). Membro do VIDELICET - Estudos em Intolerância, Diversidade e Imaginário. Vinculado ao PPGCR/UFPB e ao CNPq.

E-mail: andersoncm16@hotmail.com 


\begin{abstract}
He advent of the charismatic movement at the end of the twentieth century powered a reconfiguration of Catholicism and traditional, whose greatest expression checks with the emergence of a new way of living the Christian faith by means of the New Communities of Charismatic. In this sense, we analyze in this work, the Catholic Community in the Work of Mary, highlighting relevant aspects, as well as their development, their structure, their social projects, their community life, their role in the Church, and their religious practices. For both, we have adopted the descriptive nature of the literature. We take as reference the Work of Carranza, Mariz and Suede (2009), as well as the concept of community action of religion, according to Weber (1991), which allows us to understand the meaning through the experiences, representations and purposes subjective of individuals. Thus, from the practices that emerge within this movement, we examine the meaning that it has among its fans, and to the Church today.
\end{abstract}

Keywords: New Movements. Catholicism. Religiosity

\title{
Introdução
}

O Papa João Paulo II caracterizou o movimento das Novas Comunidades Carismáticas como [...] "um dos frutos mais significativos da Primavera da Igreja prenunciada pelo Concílio Vaticano II"1. Sem dúvida, este movimento representa uma novidade para a tradição secular católica, visto que possibilitou uma maior participação dos leigos na Igreja e contribuiu com a modernização em muitos aspectos da tradição religiosa cristalizada ao longo dos séculos.

Rompendo com o clericalismo e o distanciamento tradicional do povo com a paróquia, as Novas Comunidades são um movimento leigo surgido no final do século $\mathrm{XX}$, que apresentou um rápido crescimento em todo o mundo, caracterizando-se por colocar leigos casados e/ou solteiros, sacerdotes, religiosos e religiosas, vivendo em uma mesma estrutura e ocupando os mesmos cargos, dividindo as mesmas funções, fazendo os mesmos votos, respeitando o estado de vida no qual estão inseridos. ${ }^{2}$

Oriunda do Concilio Vaticano II, que renovou a Igreja, o movimento das Novas Comunidades teve sua origem a partir dos grupos de oração da Renovação Carismática Católica e encontrara seu lugar na Igreja com base no Pontificado do Papa João Paulo II, que afirmou:

1 JOÃO PAULO II, Papa. Mensagem do Papa João Paulo II aos participantes do Congresso Mundial dos Movimentos Eclesiais. Roma, 27 de maio de 1998. Disponível em: <http://www.vatican.va/roman_curia/pontifical_councils/laity/documents/rc_pc_laity_doc_27051998_movements-mes-hf_po.html>. Acesso em: 12 jan. 2018.

2 FERREIRA, Wagner. A formação da consciência moral nas novas comunidades. São Paulo: Canção Nova, 2011. 
É desta providencial redescoberta da dimensão carismática da Igreja foi que, antes e depois do Concílio, se consolidou uma singular linha de desenvolvimento dos movimentos eclesiais e das novas comunidades. Hoje, a Igreja alegra-se ao constatar o renovado cumprimento das palavras do profeta Joel, que há pouco escutámos: "Derramarei o Meu Espirito sobre toda a criatura" (Act 2,17). Vós aqui presentes sois a prova palpável desta efusão do Espírito.

Neste sentido, procuramos analisar, neste trabalho, a Comunidade Católica Obra de Maria, considerando aspectos relevantes para a compreensão deste movimento, bem como da realidade do catolicismo na atualidade. Para tanto, adotamos a pesquisa descritiva e de natureza bibliográfica, tendo como fundamentação teórica a Obra de Carranza, Mariz e Camurça (2009), e o caráter de ação comunitária da religião, conforme Max Weber (1991), que nos permite compreender o sentido através das vivências, das representações e dos fins subjetivos dos indivíduos. Para coleta de dados, trabalhamos com fichamento e análise de textos, documentos, e demais recursos que favoreceram a pesquisa, além da observação participante realizada nos retiros e eventos da comunidade, que permitiu não apenas a descrição do objeto, mas também a interação com o universo da pesquisa.

Desta forma, este estudo enquadra-se na perspectiva da História das religiões pois "[...] ao estudar determinado grupo religioso, pretendem-se conhecer atitudes, sentimentos, sociabilidades e práticas religiosas de homens e mulheres concretos, inseridos num determinado contexto histórico"3. Acreditamos que este trabalho tem a sua relevância na tentativa de contribuir para uma melhor compreensão não apenas desse grupo especifico, mas da realidade mais ampla do movimento das Novas Comunidades no Brasil, como também do catolicismo na atualidade.

\section{O Concilio Vaticano II e a RCC}

Das muitas mudanças ocorridas na Igreja ao longo dos séculos visto que esta sempre se adaptou as exigências dos tempos e das culturas em que estava inserida - as mudanças provocadas pelo Concílio Vaticano II são as mais expressivas nas ultimas décadas, como a permissão para

3 SILVA, Elizete da. História das Religiões: perspectivas e abordagens. In: QUADROS, Eduardo G; SILVA, Maria Conceição (Org.) Sociabilidades religiosas: mitos, ritos e identidades. São Paulo. Paulinas: 2011. p. 209-221. 
a celebração da missa na língua própria de cada país e a desobrigação do uso da batina pelo clero.

O Concílio Vaticano II (1962-1965) fora convocado pelo Papa João XXIII, canonizado juntamente com o Papa João Paulo II em 27 de abril de 2014. Este concílio reformou a Igreja, como elucida o discurso de abertura em que o Papa, dizia: "Abri as janelas para que os ventos da História soprassem a poeira do Trono de Pedro"'4 Nas palavras do Papa, portanto, o objetivo do Concílio foi o de arejar a Igreja permitindo que uma "brisa fresca" envolvesse uma instituição que parecia estar "fedendo a mofo." Este concílio, que durou quatro anos, revolucionou a Igreja, pois questionou a tradição "empoeirada" de um catolicismo abalado por muitos movimentos como o avanço do protestantismo.

Nessa perspectiva, as Novas Comunidades surgem na efervescência característica do período em que viu se proliferar uma grande quantidade de movimentos religiosos, como a New Age e outros movimentos que parecem desafiar, no campo das ideias, aquele conceito proposto por Weber do "desencantamento do mundo" em que as religiões estariam sendo banidas para os espaços particulares, não exercendo nenhuma influência significativa na cultura contemporânea. "A eclosão destes movimentos nas décadas de 70 e 80 passaram a sugerir [...] uma reorientação, ou revisão completa do conceito de secularização"s.

Neste sentido, como fruto do Concílio Vaticano II, surge a Renovação Carismática Católica, RCC, na Irlanda, no ano de 1967. Com um retiro de estudos na Universidade de Duquesne (Pittsburgh, Pensilvânia, EUA). Caracterizado como um movimento de experiências místicas, o movimento carismático obteve um crescimento muito rápido em toda a Igreja, chegando ao Brasil em 1970-71 com os padres Haroldo Joseph Rahm e Eduardo Dougherty. A Renovação Carismática tornou-se muito conhecida pelas manifestações místicas comuns em suas reuniões ou grupos de oração carismáticos, como o fenômeno do repouso no espírito, a glossolalia ou "oração em línguas", dons de revelação etc. Elementos característicos dos movimentos pentecostais americanos que revolucio-

4 JOÃO XXIII, Papa. Discurso de Sua Santidade Papa João XXIII na abertura solene do ss. Concílio. Roma, 11 de outubro de 1962. Disponivel em <https://w2.vatican.va/ content/john-xxiii/pt/speeches/1962/documents/hf_j-xxiii_spe_19621011_opening-council.html> Acesso em: 14 jan. 2018.

5 CAMURÇA, Marcelo. Ciências sociais da religião: Polêmicas e interlocuções. São Paulo: Paulinas, 2008. p. 96. 
naram o tradicionalismo católico. Para Reginaldo Prandi, a RCC é um movimento duplamente reacionário: "Para dentro do catolicismo, porque se "opõe" à Teologia da Libertação; para fora, compete com os evangélicos pentecostais na disputa pelos conversos desejosos de experiência religiosa sensível, de maior imanência do sagrado 6 ."

É neste contexto que surge o Movimento das Novas Comunidades Carismáticas Católicas, originalmente em 1970, na França e nos EUA. No Brasil, este movimento chega ainda na década de 70 com a fundação da comunidade Canção Nova/SP, que mantêm atualmente um sistema de comunicação pela internet, rádio e TV aberta. Em maio de 1998, reunidos no Vaticano para a celebração de pentecostes, os membros destes dois movimentos (RCC e NCC) receberam do Papa João Paulo II o reconhecimento da importância destes movimentos para a igreja.

Os Movimentos representam um dos frutos mais significativos daquela primavera da Igreja já prenunciada pelo Concílio Vaticano II, mas infelizmente não raro obstaculizada pelo difundido processo de secularização. A sua presença é encorajadora, porque mostra que esta primavera progride, manifestando o vigor da experiência cristã sobre o encontro pessoal com Cristo. ${ }^{7}$

Cabe ressaltar que os dois últimos Papas também demonstraram seu apoio a estes movimentos, especialmente o Papa Francisco, que fora assessor espiritual da Conferência Episcopal da Renovação Carismática na Argentina, enquanto ainda cardeal. ${ }^{8}$

Ressalte-se que, justamente por representarem uma "novidade" diante do tradicionalismo católico, as Novas Comunidades ainda são alvo de críticas por parte de alguns setores mais conservadores da Igreja. É comum, entre os membros deste movimento, relatos de "perseguições" por parte de alguns grupos e movimentos mais tradicionais, bem como de parte do clero mais conservador. Para Lopes e Miranda (2016), estas

6 PRANDI, Reginaldo. Um sopro do Espirito: A renovação conservadora do espírito carismático. 2. ed. São Paulo: Edusp/Fapesp, 1998. p. 15-16.

7 JOÃO PAULO II, Papa. Mensagem do Papa João Paulo II aos participantes do Congresso Mundial dos Movimentos Eclesiais. Roma, 27 de maio de 1998. Disponível em: <http://www.vatican.va/roman_curia/pontifical_councils/laity/documents/rc_pc_laity_doc_27051998_movements-mes-hf_po.html>. Acesso em: 12 jan. 2018.

8 FRANCISCO, PAPA. Discurso do Papa Francisco aos membros da Renovação no Espírito Santo. Roma, 3 de Julho de 2015. Disponível em: <https://w2.vatican.va/content/ francesco/pt/speeches/2015/july/documents/papa-francesco_20150703_movimento-rinnovamento-spirito.html> Acesso em: 12 jan. 2017. 
tensões entre líderes leigos e clérigos, revelam uma disputa de poder existente no interior da própria Igreja, que por muito tempo, esteve fortemente concentrado nas mãos dos religiosos e religiosas.

[...] a participação ativa na liderança por parte dos leigos, especialmente nas atividades pastorais e cargos como missionários, formação teológica e animação litúrgica evidenciam uma prática diferenciada, ou uma catolicidade que, diferente da catolicidade clerical, tem por base a santificação do indivíduo em última instância ${ }^{9}$

Contudo, o crescimento deste movimento em todo o Brasil, tem despertado a necessidade cada vez mais crescente para um diálogo mais aberto, e a adequação da estrutura do movimento à realidade eclesial. De modo que, os conflitos entre padres e membros das NCCs tem se tornado cada vez menos frequentes, uma vez que a própria $\mathrm{CNBB}$, tem se esforçado constantemente para a orientação dos padres e dos membros deste movimento, estimulando o constante dialogo por meio de encontros, seminários e documentos pastorais, no intuito de promover a adaptação da Igreja aos novos tempos. ${ }^{10}$

\section{As novas comunidades carismáticas: aspectos gerais}

Como visto anteriormente, as novas comunidades, tiveram um rápido crescimento, de modo que, hoje, são um dos maiores movimentos da Igreja Católica. No Brasil, e especialmente no Nordeste brasileiro, vemos a proliferação do número de comunidades fundadas, ultrapassando a estimativa de 500 fundações ${ }^{11}$. Este movimento configura-se como uma associação de fieis, na grande maioria leigos, que deixam família, emprego fixo, e dedicam-se integralmente às atividades próprias da comunidade a qual se consagram. Prestando serviço de ordem social e espiritual.

9 LOPES, Robson Wander C; MIRANDA, Tânia N. O. Novas comunidades católicas: entre a tradição e a modernidade. Terceira margem Amazônia, v. 2, n. 6, 2016, p. 113.

10 Ressalte-se a publicação dos Subsídios Doutrinais da CNBB: Igreja particular, movimentos eclesiais e novas comunidades. Edições CNBB, 2009. Além dos encontros, seminários e simpósios realizados em diversas dioceses do Brasil, ressaltando a necessidade de um diálogo fecundo dos membros deste movimento e as lideranças da Igreja Católica no Brasil.

11 CARRANZA, Brenda; MARIZ, Cecília; CAMURÇA, Marcelo (Org.). Novas comunidades católicas: Em busca do espaço moderno. Aparecida: Ideias \& Letras, 2009. 
Uma forma associativa, em grande parte nova na Igreja, diferenciando-se das comunidades paroquiais, das comunidades eclesiais de base e das comunidades religiosas, bem como dos demais movimentos eclesiais. Elas podem derivar de novos movimentos ou neles se integrar, mas têm a sua especificidade em relação a eles... As novas comunidades surgem como agregação de fiéis, por iniciativa própria dos leigos ou, em alguns casos, por iniciativa de algum sacerdote dirigida aos leigos. Algumas, com o passar do tempo, recebem aprovação diocesana, na condição de associação de fiéis, através de decreto do bispo da diocese onde se deu a fundação $o^{12}$.

Todo este movimento está diretamente ligado à Fraternidade Internacional das Novas Comunidades que, atualmente, é presidida pelo nordestino Gilberto Gomes Barbosa, fundador da comunidade Obra de Maria em Pernambuco. As NCCs possuem estrutura própria, mas devem estar subordinadas ao bispo diocesano e à estrutura geral, com sede no Vaticano.

O primeiro aspecto que destacamos é a Espiritualidade do movimento. Os encontros de formação, retiros e eventos promovidos pelas comunidades são marcados por muitas experiências místicas como visões, profecias, repouso no espírito, orações em línguas, momentos fortes de oração e louvor. Desta maneira, a experiência do sagrado torna-se mais importante que o discurso doutrinário.

A participação é marcada pelo desejo de auto aperfeiçoamento de seus participantes. Há um pleno engajamento do corpo e dos sentidos na experiência religiosa, por meio do canto, dança, êxtase, glossolalia. Correlato a isto, uma grande desconfiança em relação a doutrinas, teologias e intelectualização das crenças, preferindo-se as "formas não-verbais de expressão religiosa" contidas nestes movimentos ${ }^{13}$.

Esta ênfase dada à relação pessoal com o transcendental atrai muitos jovens para os eventos promovidos pelo movimento, como shows de músicas cristãs, cristotécas ${ }^{14}$, retiros, grupos de oração e missas de cura e libertação. Neste sentido, uma segunda característica observada, consiste

12 CNBB. Igreja Particular, Movimentos Eclesiais e Novas Comunidades. Brasília, Edições CNBB,2009.

13 HERVIEU-LEGER apud CAMURÇA, Marcelo. Ciências sociais da religião: Polemicas e interlocuções. São Paulo: Paulinas, 2008. p. 97.

14 Refere-se a uma balada, com música cristã eletrônica, porém sem o uso de bebidas alcoólicas. 
na preponderância de jovens ligados ao movimento. Como observa Mariz, as [...] "Novas Comunidades, atraem jovens e imprimem um estilo de ser católico do tipo sectário (adotando aqui o conceito sociológico de seita), de prática devocional intensa e fervorosa e de fechamento em relação a sociedade mais ampla"15. O Comprometimento dos membros com a comunidade reflete-se nos compromissos que os mesmos assumem com ela, por meio dos "votos de consagração", através dos quais eles recebem, na grande maioria das vezes, um sinal visível como um Tal, uma medalha, uma aliança, uma pulseira etc. Estes símbolos representam o compromisso assumido por eles a partir de então. Os consagrados fazem votos de pobreza, castidade e obediência, além de comprometerem-se a viver uma "regra de vida" com compromissos diários de oração e espiritualidade. Mariz (2005) reconhece a preponderância de jovens na realidade das Novas Comunidades, e ressalta a subjetividade juvenil, como uma possível resposta para esta realidade.

A subjetividade juvenil é concebida como oposição aos padrões burocráticos e mercantis característicos da era moderna. Guiados pela lógica da natureza, do sentimento e da dádiva desinteressada, os jovens caracterizar-se-iam por uma índole e uma subjetividade próprias, que os aproximariam de valores comunitários presentes nas diferentes religiões, mas também de ideologias politicas que se opõem à sociedade capitalista moderna. Nesse sentido, o jovem é concebido como alguém mais propenso a atitudes heroicas e a virtuosismos religiosos, que busca a santidade e também a revolução, e que morreria por uma causa ${ }^{16}$.

Os membros das Novas Comunidades são chamados de missionários, o que representa um terceiro aspecto fundamental, para compreensão deste movimento na atualidade, o seu "espírito missionário". Os membros assumem a missão de evangelizar e levar o evangelho a todos, desta forma, as Novas Comunidades se espalham com uma velocidade impressionante, com diversas casas. A Obra de Maria-PE está presente em 16 países: Brasil, Israel, Palestina, Portugal, Itália, Vaticano, Angola, Moçambique, Costa do Marfim, Benin, Togo, Cabo Verde, Gana, Paraguai, Bolívia e Argentina, qual possui vinte e cinco casas no Brasil e, pelo menos, cinco no exterior.

15 MARIZ, Cecilia. Comunidades de vida no Espírito Santo juventude e religião. Tempo social, São Paulo, 2005. v. 17, n. 2, p. 310.

16 MARIZ, 2005, p. 257. 
A "radicalidade" configura uma outra característica deste movimento. Esta radicalidade, defendida por seus participantes, refere-se à necessidade de uma vida totalmente voltada para o evangelho. Trata-se de uma busca pela santificação pessoal. "A santificação seria o que motivaria a radicalidade e a vida em comunidade" 17 . Neste sentido, este grupo, em sua "renúncia ao mundo", protesta contra a sociedade de consumo, ao optar por uma vida mais desapegada dos bens materiais, defendendo a pobreza como virtude a ser seguido.

Estas comunidades possuem variadas formas de disciplina utilizados pra lidar com membros que provocam conflitos ou que não se encaixam nos parâmetros da ortopraxia comunitários, aqueles enfim, que não correspondem as expectativas de "santidade" encorajadas pelo movimento. Trata-se de dispositivos de controle, afim de garantir a vida de radicalidade exigidas pelo grupo. Os meios de correção utilizados, vão desde a transferência de casas, até o desligamento da comunidade. Estas punições, geralmente, são imputadas quando algum membro quebra as regras estabelecidas, e não cumprem os estatutos do movimento. Isto, garante a estas comunidades, a sustentação desta radicalidade como proposta de vida para todos os seus membros.

Por fim, destacamos, o caráter filantrópico do movimento, posto que todas as comunidades desenvolvem práticas de caridade como parte fundamental das atividades próprias do grupo. Desta forma, observam-se postos médicos, creches, casa de recuperação para dependentes químicos, visita a hospitais e asilos, distribuição de sopas para moradores de ruas etc. Para os membros do movimento, trata-se do exercício do mandamento de Cristo nos evangelhos: "Dai de comer a quem tem fome"18. Este aspecto torna-se ainda mais relevante quando consideramos que as comunidades carismáticas sustentam-se de doações, ou seja: "Podemos dizer que em certo momento histórico, crenças e valores se tornaram mais importantes do que seus bens materiais, sua sobrevivência econômica e política. Há momentos em que muitos se dispõem a pagar altíssimos preços por esses valores" 19 .

17 CARRANZA, Brenda; MARIZ, Cecília. Novas Comunidades Católicas: por que crescem? In: CARRANZA, Brenda; MARIZ, Cecília; CAMURÇA, Marcelo (Org.). Novas comunidades católicas: Em busca do espaço moderno. Aparecida: Ideias \& Letras, 2009. p. 157. Mt 14, 16 In: Bíblia sagrada. Edição Claretiana. São Paulo: Ave-Maria, 2010. Edição revisada. SOS, João Décio; USARSKI, Frank (Org.) Compêndio de Ciência da Religião. São Paulo: Paulus/Paulinas, 2013. p. 304. 


\section{A comunidade católica Obra de Maria: sociabilidades e estilo de vida}

A Comunidade Obra de Maria surgiu no ano de 1990 no bairro da Várzea, Recife-PE, sob a fundação e presidência do teólogo e psicanalista Gilberto Gomes Barbosa que, após cinco anos participando ativamente de grupos de oração da Renovação Carismática Católica e tomando por modelo as formas de vida das comunidades Canção Nova - SP e Shalom - CE, inicia esta comunidade com um grupo inicial de sete jovens dispostos a deixarem suas casas, profissões e estudos para se dedicarem integralmente ao serviço da evangelização.

Gilberto Gomes Barbosa é natural de Boca de Dois Rios, comunidade que fica na divisa entre os municípios de Surubim e Bom Jardim no interior de Pernambuco. Veio morar no Recife em 1983, aos 14 anos, para trabalhar e estudar. Conheceu a Renovação Carismática aos 16 anos, através de uma Vigília, e, a partir de então, tornou-se um membro ativo e muito atuante. Formou-se em filosofia e em teologia pelo Mosteiro São Bento em Olinda-PE, também possui formação em psicanálise. É casado, pai de três filhas e, atualmente, ocupa o cargo de presidente da Fraternidade Internacional das Novas Comunidades com sede no Vaticano, um dos cargos mais altos que um leigo poderia assumir na hierarquia da Igreja Católica. Recentemente, foi considerado o leigo mais influente da Igreja ${ }^{20}$.

Inicialmente, Gilberto participou ativamente do movimento da RCC, tendo ocupado cargos de liderança no Estado de Pernambuco. Após um caminho vocacional com a Canção Nova, discerniu, através do Próprio Monsenhor Jonas Abib, fundador da Comunidade Canção Nova, que possuía um autêntico espírito de liderança e assumiu a missão de fundador. Assim, surgiu a Comunidade Obra de Maria.

$\mathrm{Na}$ atualidade, a comunidade Obra de Maria possui 2.800 membros espalhados em diversos lugares do Brasil e do mundo. Ressalte-se que os membros da Obra de Maria, dividem-se em duas realidades: os de vida interna e os externos à estrutura. Ambos vivem a mesma regra de

20 MOURA, Aline. O leigo mais influente do mundo na hierarquia da Igreja Católica é de Pernambuco. Pernambuco, 27 maio 2017. Disponível em: <http://www.diariodepernambuco.com.br/app/noticia/brasil/2017/05/27/interna_brasil,705970/o-leigo-mais-influente-do-mundo-na-hierarquia-da-igreja-catolica-e-de.shtml>. Acesso em: 16 jan. 2018. 
vida, o mesmo diretório, possuem as mesmas obrigações e formação, a única diferença entre eles, é o fato de que os de vida interna moram nas casas de missão da comunidade, e dedicam-se integralmente às atividades missionárias, já os membros externos, não moram na estrutura, estão inseridos "no mundo", trabalham, estudam etc., mas procuram conciliar a vida secular com a realidade missionária. Os membros da comunidade fazem uso de uma medalha que os identifica, sendo que a mesma apresenta a imagem do Cristo crucificado e, aos pés da cruz, a virgem Maria e o apóstolo João. Os estados de vida que compõem a realidade dos membros da comunidade são: o sacerdócio, o matrimônio, o celibato consagrado e os solteiros. O carisma norteador das ações da Comunidade é: "Evangelizar de todas as formas com alegria." Neste sentido, esta comunidade desenvolve atividades variadas de evangelização missionária como cenáculos ${ }^{21}$, retiros, peregrinações religiosas a santuários importantes para o cristianismo, além dos grupos de oração com espiritualidade carismática.

As fases de formação para os aspirantes a missionários da comunidade são de, no mínimo, três anos. São as fases do Pré-discipulado (um ano) e Discipulado (dois anos). Após este período de formação e discernimento, o candidato deve escrever uma carta para o conselho da comunidade solicitando sua consagração, se aprovado, o membro recebe a medalha de consagração como sinal visível de sua entrega a Deus e à Igreja pelo carisma Obra de Maria.

Além dos serviços espirituais, destacamos que a comunidade Obra de Maria também presta serviços sociais, como posto médico gratuito, creches, casas de recuperação para dependentes químicos, distribuição de sopão para comunidades carentes dentre outras atividades, todas mantidas pela comunidade que sustenta-se basicamente das doações que recebe dos chamados: "Braços fortes", e da renda proveniente da agência de viagens Rainha da paz, que promove várias viagens com roteiros variados para os santuários importantes da Igreja Católica. Não obstante ser uma comunidade Carismática, a Obra de Maria também possui uma espiritualidade mariana, que se manifesta de diferentes maneiras dentro do movimento, além da devoção aos seus cinco santos protetores: São

21 Trata-se de uma evangelização específica da Obra de Maria, onde os missionários visitam mensalmente, algumas famílias devidamente cadastradas e promovem um grupo de oração familiar. Com a recitação do terço, meditação da palavra, cantos e orações. 
José, São João Evangelista, São Padre Pio, São João Paulo II e Santa Teresinha do menino Jesus.

Os fundadores da comunidade são presenças ativas na realidade deste movimento ${ }^{22}$, os membros e os fundadores se ligam afetivamente no contato constante, percebe-se, em todos os participantes da comunidade, um profundo respeito e afeto pela figura "paterna e materna" dos seus fundadores. Segundo Carranza e Mariz: "De certa forma, a vocação do "discípulo" se espelha na do fundador a quem tem fácil acesso; numa modulação quase harmônica, o seguidor encontra mais uma motivação para abraçar a causa, para fortalecer seu vínculo de pertença" ${ }^{23}$. Na tipologia Weberiana, o fundador é profeta mistagogo que herda o dom, profeta ético-religioso ao se definir como instrumento de Deus e profeta exemplar que assinala com a própria vida a salvação ${ }^{24}$. Portanto, para este autor, o papel da liderança carismática também é fundamental para a compreensão dos movimentos sociais em geral.

De acordo com Max Weber (1991), entendemos a comunidade como um lugar social de extrema importância para a reconstrução de identidades religiosas. Neste sentido, mobilizados em torno do "carisma", os membros da Obra de Maria participam de uma rede de sociabilidade intensa e densa. De acordo com Baechler:

Sociabilidade é a capacidade humana de estabelecer redes através das quais as unidades de atividades, individuais ou coletivas fazem circular as informações que exprimem os seus interesses, gostos, paixões, opiniões [...] vizinhos, públicos, salões, círculos, cortes reais, mercados, classes sociais, civilizações ${ }^{25}$.

Nesta perspectiva, percebemos, através das práticas que emergem do seio deste movimento, a interação entre seus adeptos, que se relacionam e interagem a partir de um sentimento afetivo, procedente do carisma

22 A comunidade Obra de Maria possui um fundador e uma cofundadora: Gilberto Gomes Barbosa e Maria Salomé Ventura.

23 CARRANZA, Brenda; MARIZ, Cecília. Novas Comunidades Católicas: por que crescem?. In CARRANZA, Brenda; MARIZ, Cecília; CAMURÇA, Marcelo (Org.). Novas comunidades católicas: Em busca do espaço moderno. Aparecida: Ideias \& Letras, 2009. p. 154

24 WEBER, Max. (1921). Economia e Sociedade. Fundamentos da sociologia compreensiva. Brasília: Ed. UNB, 1991. p. 361

25 BAECHLER, J. Grupos e sociabilidade. In: BOUDON, R. (Ed.). Tratado de sociologia. Lisboa: Asa, 1995. p. 57. 
da comunidade, que se configura como o "elo" entre os membros, os fundadores, e a Igreja de modo geral.

O carisma, quando emerge, tem um caráter volátil e impermanente, e gera forças transformadoras que dá coragem aos indivíduos para romper com suas rotinas, abrir mão do sentido que sempre norteou suas vidas, correr o risco da anomia, para buscar o novo, o desconhecido [...] uma ação social nessa direção somente se torna possível quando motivada por uma fé carismática [racionalmente cega], em um novo projeto ${ }^{26}$.

Portanto, percebemos que a comunidade Obra de Maria, inserida no contexto geral das Novas Comunidades, evoca em sua vivência, enquanto grupo social, um estilo de vida próprio que passa a ser assumido pelos membros a partir das formações, que retificam o compromisso de todos, na convivência fraterna, na obediência aos líderes, na evangelização contínua e no engajamento no serviço à Igreja.

\section{Considerações finais}

Pelo exposto, entendemos o movimento das Novas Comunidades Carismáticas como um movimento pós-moderno, que apresenta uma quebra ou ruptura com o tradicionalismo Católico, ao passo que aponta para uma forma de catolicismo mais pessoal, voltado para o transcendental na busca pela "santificação" dos seus adeptos. Neste contexto, a comunidade católica Obra de Maria se configura como uma comunidade engajada na missão de "evangelizar de todas as formas com alegria", sendo este o objetivo principal da vocação de seus membros, para alcançar a "santidade" por meio de uma maior "intimidade com Deus".

Por meio do carisma dos fundadores, os membros desta comunidade encontram um referencial e modelo a ser seguido, e participam de uma rede de sociabilidade proporcionada pela identidade constituída em torno do carisma do próprio grupo que permite a todos o sentimento de pertença e reciprocidade, visto que todos são considerados "irmãos" de uma grande "família".

Nosso objetivo foi, portanto, apresentar o histórico deste movimento, bem como seu desenvolvimento, destacando pontos importantes

26 MARIZ, Cecília Loreto. Instituições tradicionais e movimentos emergentes. In: PASSOS, João Décio; USARSKI, Frank (Org.) Compêndio de Ciência da Religião. São Paulo. Paulus/Paulinas. 2013. p. 304. 
para a compreensão da religiosidade católica na atualidade, a partir de um olhar especifico, destacando a realidade de uma das maiores comunidades carismáticas presentes do Brasil e no mundo.

\section{Referências}

BÍBLIA. Português. Bíblia sagrada. Edição Claretiana. São Paulo: Ave-Maria, 2010. Edição revisada.

BAECHLER, J. Grupos e sociabilidade. In: BOUDON, R. (Ed.). Tratado de sociologia. Lisboa: Asa, 1995.

CAMURÇA, Marcelo. Ciências sociais da religião: Polemicas e interlocuções. São Paulo: Paulinas, 2008. p. 97.

CARRANZA, Brenda; MARIZ, Cecília; CAMURÇA, Marcelo (Org.). Novas comunidades católicas: Em busca do espaço moderno. Aparecida: Ideias \& Letras, 2009.

CARRANZA, Brenda; MARIZ, Cecília. Novas Comunidades Católicas: por que crescem? In: CARRANZA, Brenda; MARIZ, Cecília; CAMURÇA, Marcelo (org.). Novas comunidades católicas: Em busca do espaço moderno. Aparecida: Idéias \& Letras, 2009.

CNBB. Igreja Particular, Movimentos Eclesiais e Novas Comunidades. Brasília: Edições CNBB, 2009.

FERREIRA, Wagner. A formação da consciência moral nas novas comunidades. São Paulo: Canção Nova, 2011.

JOÃO PAULO II, Papa. Mensagem do Papa João Paulo II aos participantes do Congresso Mundial dos Movimentos Eclesiais. Roma, 27 de maio de 1998. Disponível em: <http://www.vatican.va/roman_curia/ pontifical_councils/laity/documents/rc_pc_laity_doc_27051998_movements-mes-hf_po.html>. Acesso em: 12 jan. 2018.

JOAO XXIII, Papa. Discurso de Sua Santidade Papa João XXIII na abertura solene do ss. Concílio. Roma, 11 de outubro de 1962. Disponivel em: <https://w2.vatican.va/content/john-xxiii/pt/speeches/1962/ documents/hf_j-xxiii_spe_19621011_opening-council.html >. Acesso em: 14 jan. 2018.

LOPES, Robson Wander C; MIRANDA, Tânia N. O. Novas comunidades católicas: entre a tradição e a modernidade. Terceira margem Amazônia, v. 2, n. 6, p. 99-114, 2016. 
MARIZ, Cecília Loreto. Instituições tradicionais e movimentos emergentes. In: PASSOS, João Décio; USARSKI, Frank (Org.). Compêndio de Ciência da Religião. São Paulo: Paulus/Paulinas, 2013. p. 301-312. . Comunidades de vida no Espírito Santo juventude e religião. Tempo social, São Paulo, v. 17, n. 2, p. 253-273, 2005.

MOURA, Aline. O leigo mais influente do mundo na hierarquia da Igreja Católica é de Pernambuco. Pernambuco, 27 maio 2017. Disponível em: $<$ http://www.diariodepernambuco.com.br/app/noticia/brasil/2017/05/27/ interna_brasil,705970/o-leigo-mais-influente-do-mundo-na-hierarquia-da-igreja-catolica-e-de.shtml>. Acesso em: 16 jan. 2018.

PRANDI, Reginaldo. Um sopro do Espirito: A renovação conservadora do espírito carismático. 2. ed. São Paulo: Edusp/Fapesp, 1998.

SILVA, Elizete da. História das Religiões: perspectivas e abordagens. In: QUADROS, Eduardo G; SILVA, Maria Conceição (Org.) Sociabilidades religiosas: mitos, ritos e identidades. São Paulo. Paulinas: 2011. p. 209-221.

WEBER, Max. (1921). Economia e Sociedade. Fundamentos da sociologia compreensiva. Brasília: Ed. UNB, 1991. 